\title{
Hemoglobin decline in cancer patients receiving chemotherapy without an erythropoiesis-stimulating agent
}

\author{
Robert Pirker • Melissa Pirolli • Jane Quigley • Scott Hulnick • \\ Jason Legg • Helen Collins • Johan Vansteenkiste
}

Received: 9 July 2012 / Accepted: 26 September 2012 /Published online: 25 October 2012

(C) The Author(s) 2012. This article is published with open access at Springerlink.com

\begin{abstract}
Purpose The aim of this study was to examine the rate and timing of hemoglobin decline from $<10 \mathrm{~g} / \mathrm{dL}$ to $<9 \mathrm{~g} / \mathrm{dL}$ in cancer patients receiving chemotherapy.

Methods Pooled data from the placebo arms of six randomized, controlled trials (RCTs) of darbepoetin alfa and data from an aggregated US community oncology clinic electronic medical records (EMR) database were analyzed. Patients had baseline hemoglobin $\geq 10 \mathrm{~g} / \mathrm{dL}$ (RCTs) or baseline hemoglobin between $\geq 10 \mathrm{~g} / \mathrm{dL}$ and $<11 \mathrm{~g} / \mathrm{dL}$ (EMR episodes) that declined to $<10 \mathrm{~g} / \mathrm{dL}$ at least once during the study period. The proportion of patients/episodes with hemoglobin decline to $<9 \mathrm{~g} / \mathrm{dL}$ by 3,6 , and 9 weeks without erythropoiesis-stimulating agents was estimated from data in each of the data sources, as was the rate of transfusions in the RCTs.
\end{abstract}

\author{
R. Pirker \\ Medical University Vienna, \\ Währinger Gürtel 18-20, \\ 1090 Vienna, Austria \\ M. Pirolli · J. Quigley $\cdot$ S. Hulnick \\ SDI Health, \\ One IMS Drive, \\ Plymouth Meeting, PA 19462, USA \\ J. Legg $\cdot$ H. Collins \\ Amgen Inc., \\ One Amgen Center Drive, \\ Thousand Oaks, CA 91320, USA \\ J. Vansteenkiste \\ University Hospital Gasthuisberg, \\ Herestraat 49, \\ 3000 Leuven, Belgium \\ R. Pirker $(\bowtie)$ \\ Department of Medicine I, Medical University Vienna, \\ Vienna, Austria \\ e-mail: robert.pirker@meduniwien.ac.at
}

Results Data from 411 patients receiving placebo in the RCTs and 10,523 patients (10,942 episodes) in the EMR database were analyzed. Forty percent and $35 \%$ of RCT patients and EMR episodes, respectively, had a hemoglobin decline from $<10 \mathrm{~g} / \mathrm{dL}$ to $<9 \mathrm{~g} / \mathrm{dL}$ at week $3,54 \%$ and $43 \%$ at week 6 , and $58 \%$ and $46 \%$ at week 9 . Of patients in the RCTs, $43 \%$ required an RBC transfusion.

Conclusions Hemoglobin can rapidly decline in cancer patients receiving chemotherapy with hemoglobin levels around $10 \mathrm{~g} / \mathrm{dL}$, particularly in patients $\geq 65$ years of age. The rapid rate of hemoglobin decline in these patients should be considered for optimal anemia management.

Keywords Anemia $\cdot$ Hemoglobin $\cdot$ Chemotherapy · Transfusion · Elderly

\section{Introduction}

Anemia is common in cancer patients receiving chemotherapy and is associated with poor clinical outcomes [1]. Chemotherapy-induced anemia can be treated with erythropoiesis-stimulating agents (ESAs), red blood cell (RBC) transfusions, or both. According to current ESA labels, treatment with ESAs in patients receiving chemotherapy should not be considered until hemoglobin levels are less than $10 \mathrm{~g} / \mathrm{dL}$ in the USA or at or below $10 \mathrm{~g} / \mathrm{dL}$ in the EU [2-4]. However, ESAs take time to induce a hemoglobin response and therefore are not suitable for patients who require immediate correction of anemia [5]. Studies have suggested that initiating an ESA when hemoglobin is between $9 \mathrm{~g} / \mathrm{dL}$ and $10 \mathrm{~g} / \mathrm{dL}$ results in fewer transfusions compared with initiating an ESA when hemoglobin is $<9 \mathrm{~g}$ / dL [6-8]. However, not all patients whose hemoglobin is in the $9 \mathrm{~g} / \mathrm{dL}$ to $10 \mathrm{~g} / \mathrm{dL}$ range will continue to fall to levels of $<9 \mathrm{~g} / \mathrm{dL}$, and because ESAs have risks, the decision of when 
to initiate an ESA is partially informed by the rate of hemoglobin decline and the likelihood that the patient will require a transfusion if they do not receive the ESA. Few data are available regarding the proportion of patients with hemoglobin in the range of $9 \mathrm{~g} / \mathrm{dL}$ to $<10 \mathrm{~g} / \mathrm{dL}$ who will experience a hemoglobin decline to $<9 \mathrm{~g} / \mathrm{dL}$ or the rate at which the decline occurs. A better understanding of factors that influence the rate of hemoglobin decline from $10 \mathrm{~g} / \mathrm{dL}$ to $9 \mathrm{~g} / \mathrm{dL}$ may assist oncologists in optimizing the use of ESAs in patients receiving chemotherapy.

We examined rates of hemoglobin decline using two types of data: (1) from patients enrolled in randomized, placebocontrolled clinical trials (RCTs) and (2) from community oncology clinic electronic medical records (EMRs). RCTs with placebo control are usually considered the gold standard of clinical evidence; however, results from these trials, which were initiated in the late 1990s, may not reflect real-world contemporary oncology care in 2012. The purpose of this analysis was to estimate the proportion of patients from pooled data from six RCTs whose hemoglobin declined from a level of $<10 \mathrm{~g} / \mathrm{dL}$ to $<9 \mathrm{~g} / \mathrm{dL}$ and the proportion of patients who further declined to a level that required a transfusion in the absence of treatment with an ESA. As these data were up to 10 years old, we wanted to determine if these results would also be applicable to a contemporary USA patient population and therefore performed the same analysis using data from an EMR database; transfusions are not routinely collected in outpatient EMRs, so the transfusion endpoint could not be evaluated in the patients in the EMR database.

\section{Patients and methods}

\section{Study design}

We analyzed data from two sources: pooled data from the placebo arms of six RCTs of darbepoetin alfa and data from an aggregated US community oncology clinic EMR database maintained by SDI Health. The EMR database included 385,000 annual cancer patients from the USA who had documented hemoglobin values. Data used in this analysis were obtained from 63 outpatient oncology practices.

\section{Patients}

The darbepoetin alfa RCTs included patients with solid tumors [9], lung cancer [10, 11], lymphoproliferative malignancies [12, 13], and multiple tumor types [14]. The subset of placebo patients in these studies who had a baseline hemoglobin $\geq 10 \mathrm{~g} / \mathrm{dL}$ and reported at least one hemoglobin value $<10 \mathrm{~g} / \mathrm{dL}$ during the study treatment period (length of trial was 16 weeks for five RCTs and 24 weeks for one RCT) were included in the analysis. In the original studies, patients had a baseline hemoglobin level of $\leq 11.0 \mathrm{~g} / \mathrm{dL}$ in four studies $[9,10,12,13],<11.0 \mathrm{~g} / \mathrm{dL}$ in one study [14], and $\geq 9 \mathrm{~g} / \mathrm{dL}$ in one study [11].

To closely mirror the criteria of the RCTs, eligible patients in this analysis from the EMR database were $\geq 18$ years old with nonmyeloid malignancies and index hemoglobin $\geq 10 \mathrm{~g} / \mathrm{dL}$ and $<11 \mathrm{~g} / \mathrm{dL}$ on or after the start of the chemotherapy episode, with an index hemoglobin date between August 1, 2008 and June 26, 2010. EMR-eligible patients also had received a myelosuppressive chemotherapy doublet (two chemotherapy drugs) between August 1, 2008 and June 26, 2010. Patients could be on any cycle of their chemotherapy regimen as long as they received $\geq 2$ additional chemotherapy cycles at $\leq 35$-day intervals after their index hemoglobin level of $10 \mathrm{~g} / \mathrm{dL}$ to $11 \mathrm{~g} / \mathrm{dL}$. Chemotherapy episodes were re-indexed when the hemoglobin level was $<10 \mathrm{~g} / \mathrm{dL}$ to estimate the proportions of episodes and patients that further declined to hemoglobin $<9 \mathrm{~g} / \mathrm{dL}$ by 3,6 , and 9 weeks without ESA therapy.

EMR-eligible patients could not have received an ESA within 9 weeks before the date when hemoglobin was $10 \mathrm{~g} /$ $\mathrm{dL}$ to $11 \mathrm{~g} / \mathrm{dL}$ or at any time during the 18 -week study period unless hemoglobin was $<9 \mathrm{~g} / \mathrm{dL}$. The doublet chemotherapy regimen contained one drug from one of the following categories: anthracycline (doxorubicin, epirubicin, mitoxantrone, liposomal doxorubicin), taxane (paclitaxel, docetaxel, nanoparticle albumin-bound [nab]-paclitaxel), platinum (cisplatin, carboplatin, not oxaliplatin), or gemcitabine. These doublets were chosen to be consistent with a prior non-Amgen publication that analyzed chemotherapyinduced anemia prevalence and incidence in the USA [15]. Chemotherapy was administered at $\leq 35$-day intervals during the first 9 weeks of the study period or until hemoglobin declined to $<9 \mathrm{~g} / \mathrm{dL}$, whichever occurred first.

\section{Study endpoints}

For patients enrolled in the RCTs, study endpoints included the occurrence of hemoglobin decline from $<10 \mathrm{~g} / \mathrm{dL}$ to $<9 \mathrm{~g} / \mathrm{dL}$ or transfusion by weeks 3, 6, and 9 after hemoglobin $<10 \mathrm{~g} / \mathrm{dL}$ was reached. For patients included in the EMR database, study endpoints were the proportion of patients with hemoglobin decline from the $10 \mathrm{~g} / \mathrm{dL}$ to $11 \mathrm{~g} / \mathrm{dL}$ range to $<10 \mathrm{~g} / \mathrm{dL}$ within 3,6 , and 9 weeks and of those episodes with hemoglobin $<10 \mathrm{~g} / \mathrm{dL}$, further hemoglobin decline to $<9 \mathrm{~g} / \mathrm{dL}$ within 3,6 , and 9 weeks. EMR databases do not reliably capture transfusions that occur outside the clinic setting, and transfusions were therefore not evaluated for patients in the EMR database.

Statistical considerations

Kaplan-Meier point estimates and associated $95 \%$ confidence intervals (CIs) were provided for time-to-event 
analyses for patients enrolled in the RCTs. Data were stratified by sex, age ( $<65$ and $\geq 65$ years), tumor type, and chemotherapy type (platinum and other). EMR data were also stratified by sex, age, tumor type, and chemotherapy type (platinum, taxane, anthracycline, or gemcitabine). Index hemoglobin date was defined as the date of first qualifying hemoglobin level $(\geq 10 \mathrm{~g} / \mathrm{dL}$ and $<11 \mathrm{~g} / \mathrm{dL}$ within 7 days of chemotherapy administration). Index chemotherapy date was defined as the date chemotherapy was received.

\section{Results}

Patients

This analysis included 411 placebo patients who had baseline hemoglobin $\geq 10 \mathrm{~g} / \mathrm{dL}$ and at least one hemoglobin value $<10 \mathrm{~g} / \mathrm{dL}$ enrolled in RCTs and 10,523 patients (representing 10,942 chemotherapy episodes) with hemoglobin $\geq 10 \mathrm{~g} / \mathrm{dL}$ and $<11 \mathrm{~g} / \mathrm{dL}$ in the EMR database. Approximately half of the patients enrolled in the RCTs were men (59\%) and patients represented in the EMR database were predominantly women $(72 \%)$ (Table 1$)$. Similar proportions of patients were $\geq 65$ years of age ( $43 \%$ of patients in the RCTs and $39 \%$ of patients in the EMR database). Tumor types differed between the RCT and EMR patients; the predominant tumor types were lung cancer and breast cancer in the RCTs and EMR database, respectively. Chemotherapy regimens differed between the two sets of patients; most (78\%) patients in the RCTs received platinum-based regimens compared with $58.6 \%$ of patients in the EMR database. Additionally, $66.4 \%$ of patients in the EMR database received taxane-based chemotherapy (patients in the EMR database could be counted in more than one chemotherapy category; e.g., carboplatin and paclitaxel would be included in both "platinum" and "taxane" categories).

Hemoglobin decline

Similar proportions of patients in the RCTs and EMR database experienced a decline in hemoglobin to $<9 \mathrm{~g} / \mathrm{dL}$ at weeks 3, 6, and 9 (Table 2). Because the majority of placebo patients in the RCTs had received a platinum and/or had lung cancer, patients who received a platinum and/or had lung cancer in the EMR database were analyzed separately; similar proportions of such patients in the RCTs and episodes in the EMR
Table 1 Patient demographics and disease characteristics at baseline

\footnotetext{
${ }^{\mathrm{a}}$ Includes only patients who had hemoglobin $\geq 10 \mathrm{~g} / \mathrm{dL}$ and had hemoglobin $<10 \mathrm{~g} / \mathrm{dL}$ at least once during the study

$S D$ standard deviation $R C T$ randomized controlled trials $E M R$ electronic medical records
}

\begin{tabular}{|c|c|c|c|}
\hline & \multirow{2}{*}{$\begin{array}{l}\text { RCT patients }{ }^{\mathrm{a}} \\
\text { Placebo }(N=411)\end{array}$} & \multicolumn{2}{|l|}{ EMR patients } \\
\hline & & All patients $(N=10,523)$ & All episodes $(N=10,942)$ \\
\hline Women, $n(\%)$ & $168(41)$ & $7,565(72)$ & $7,825(72)$ \\
\hline Age, mean years (SD) & $62.5(10.1)$ & & \\
\hline Age $\geq 65$ years, $n(\%)$ & $175(43)$ & $4,147(39)$ & $4,321(39)$ \\
\hline Race, White $n(\%)$ & $397(97)$ & & \\
\hline \multicolumn{4}{|l|}{ Tumor type, $n(\%)$} \\
\hline Breast & $18(4)$ & $4,353(41)$ & $4,418(40)$ \\
\hline Gastrointestinal & $14(3)$ & & \\
\hline Genitourinary & $5(1)$ & & \\
\hline Gynecologic & $12(3)$ & $899(9)$ & $961(9)$ \\
\hline Hematologic & $56(14)$ & & \\
\hline Lung & $297(72)$ & $3,071(29)$ & $3,257(30)$ \\
\hline Other & $9(2)$ & $2,200(21)$ & $2,306(21)$ \\
\hline \multicolumn{4}{|l|}{ Stage, $n(\%)$} \\
\hline I/II or lower/limited & $39(10)$ & & \\
\hline III/IV or higher/extensive & $361(88)$ & & \\
\hline Other & $6(1)$ & & \\
\hline Unknown & $5(1)$ & & \\
\hline \multicolumn{4}{|l|}{ Chemotherapy regimen, $n(\%)$} \\
\hline Anthracycline & & $3,017(29)$ & $3,050(28)$ \\
\hline Taxane & & $7,075(67)$ & $7,269(66)$ \\
\hline Platinum & & $6,100(58)$ & $6,408(59)$ \\
\hline Gemcitabine & & $1,465(14)$ & $1,504(14)$ \\
\hline Hemoglobin, mean g/dL (SD) & $11.26(0.98)$ & & \\
\hline
\end{tabular}


Table 2 Proportion of patients with hemoglobin decline from $<10 \mathrm{~g} / \mathrm{dL}$ to $<9 \mathrm{~g} / \mathrm{dL}$

\begin{tabular}{|c|c|c|c|c|}
\hline \multirow{2}{*}{$\begin{array}{l}\text { Patients or episodes with hemoglobin } \\
\text { decline, } \%(95 \% \text { CI })\end{array}$} & \multirow{2}{*}{$\begin{array}{l}\text { RCT patients }{ }^{\mathrm{a}} \\
\text { Placebo } \\
(n=411)\end{array}$} & \multicolumn{3}{|l|}{ EMR episodes ${ }^{\mathrm{b}}$} \\
\hline & & $\begin{array}{l}\text { All episodes } \\
(n=5,535)\end{array}$ & $\begin{array}{l}\text { Lung cancer episodes } \\
(n=1,804)\end{array}$ & $\begin{array}{l}\text { Episodes with a platinum } \\
\text { doublet }(n=3,489)\end{array}$ \\
\hline Week 3 & $40 \%(35,45)$ & $35 \%(34,37)$ & $42 \%(40,44)$ & $40 \%(38,41)$ \\
\hline Week 6 & $54 \%(49,59)$ & $43 \%(41,44)$ & $48 \%(46,51)$ & $47 \%(46,49)$ \\
\hline Week 9 & $58 \%(53,63)$ & $46 \%(44,47)$ & $51 \%(49,54)$ & $51 \%(49,53)$ \\
\hline
\end{tabular}

${ }^{a}$ Values represent Kaplan-Meier percentage estimates

${ }^{\mathrm{b}}$ Values represent crude percentages

$R C T$ randomized controlled trials, EMR electronic medical records $C I$ confidence interval

database had a hemoglobin decline from $<10 \mathrm{~g} / \mathrm{dL}$ to $<9 \mathrm{~g} / \mathrm{dL}$. Most events of hemoglobin decline to $<9 \mathrm{~g} / \mathrm{dL}$ occurred within 3 weeks of chemotherapy, including $40 \%$ of patients in the RCTs and $35 \%$ of episodes in the EMR database. Within 9 weeks, hemoglobin had declined to $<9 \mathrm{~g} / \mathrm{dL}$ in $58 \%$ of patients in the RCTs (Fig. 1) and $46 \%$ of episodes in the EMR database.

The percentage $(95 \% \mathrm{CI})$ of chemotherapy episodes in the EMR database with a decline in hemoglobin to $<9 \mathrm{~g} / \mathrm{dL}$ within 3 weeks was $38.3 \%(6.3,40.3)$ for patients 65 years of age and older and $33.5 \%(31.9,35.2)$ for patients under 65 years of age (Fig. 2). At 9 weeks, the percentages (95\% CI) were $49.0 \%(46.9,51.1)$ and $43.4 \%(41.8,45.1)$ for episodes with a decline in hemoglobin to $<9 \mathrm{~g} / \mathrm{dL}$ for patients $\geq 65$ years and $<65$ years, respectively.

\section{$\mathrm{RBC}$ transfusion}

Of the 411 placebo patients enrolled from the RCTs, 178 (43\%) required an RBC transfusion for their anemia (Table 3). By week 9 , over one third of patients (39\%) had undergone at least one RBC transfusion.

\section{Discussion}

Not all patients on chemotherapy whose hemoglobin has declined to the $9 \mathrm{~g} / \mathrm{dL}$ to $10 \mathrm{~g} / \mathrm{dL}$ range will continue to fall to levels of $<9 \mathrm{~g} / \mathrm{dL}$ or require a transfusion. Determining potential risk factors for a hemoglobin decline and the rate of hemoglobin decline would ideally be addressed by a prospective RCT. All the data presented here are retrospective, representing either an unplanned retrospective subgroup analysis of RCT data or retrospective EMR data. As such, the data presented here are hypothesis-generating only.

The data reported here from placebo patients in RCTs suggested that for patients receiving chemotherapy with a hemoglobin decline to $<10 \mathrm{~g} / \mathrm{dL}$, hemoglobin levels subsequently transition quickly to $<9 \mathrm{~g} / \mathrm{dL}$. The proportion of chemotherapy episodes where hemoglobin declined to $<9 \mathrm{~g} / \mathrm{dL}$ was similar regardless of age. Consistent with the known enhanced hematotoxicity in elderly patients [16, 17], the hemoglobin decline was slightly more pronounced in patients over 65 years. Despite expected differences between patients enrolled in global RCT trials 10 years ago and patients currently being treated in US community
Fig. 1 Time to hemoglobin decline from $<10 \mathrm{~g} / \mathrm{dL}$ to $<9 \mathrm{~g} /$ $\mathrm{dL}$ in patients enrolled in RCTs. The Kaplan-Meier analysis of time to hemoglobin decline is shown. Gray shading represents $95 \%$ confidence intervals

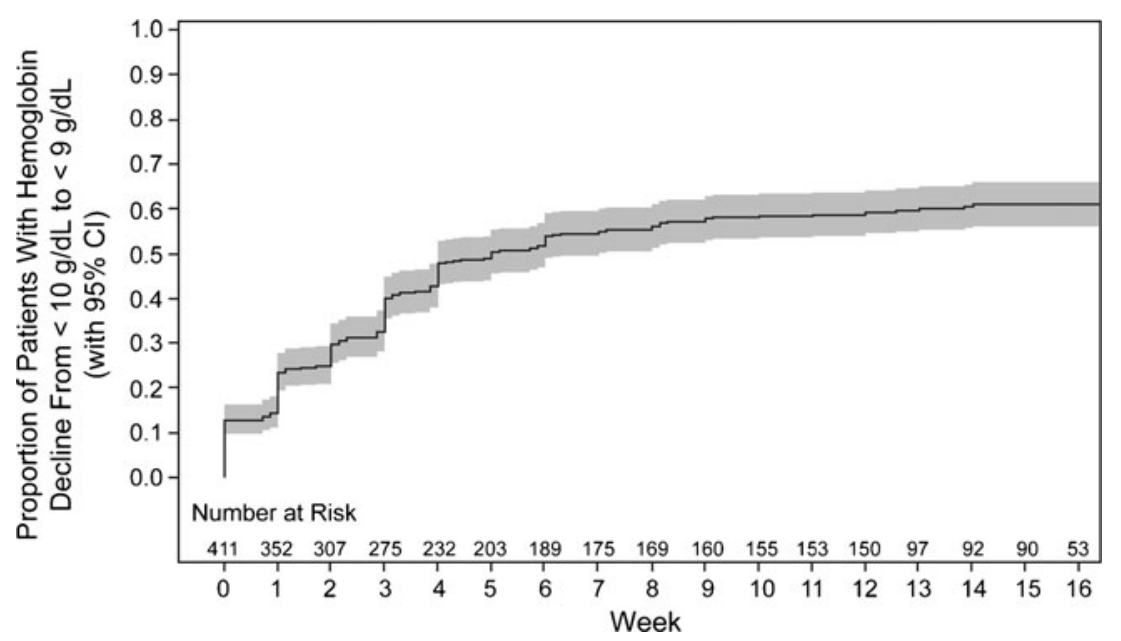




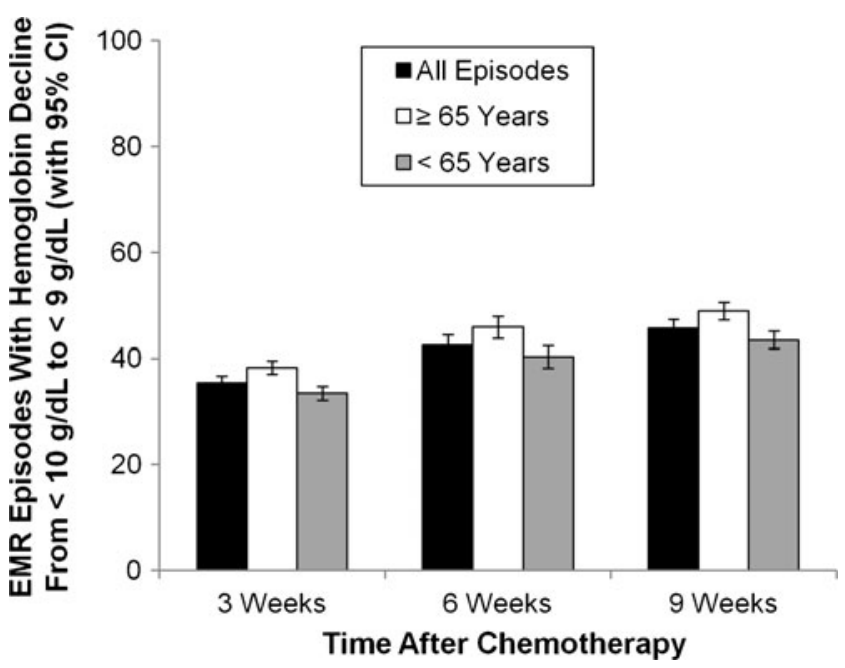

Fig. 2 Hemoglobin decline by age group in patients in the EMR database. The proportion of all chemotherapy episodes (black bars), episodes for patients $\geq 65$ years of age (white bars), and episodes for patients $<65$ years of age (gray bars) with hemoglobin decline from $<10 \mathrm{~g} / \mathrm{dL}$ to $<9 \mathrm{~g} / \mathrm{dL}$ are shown

oncology practices, patients with the same tumor types and receiving similar chemotherapy doublets experienced similar rates of hemoglobin decline.

Most of the placebo patients enrolled in the RCTs had lung cancer and/or had received platinum chemotherapy, whereas many cancer types were represented in the EMR database and the most common chemotherapy was taxane. The predominant cancer type represented in the EMR database was breast cancer. Also, EMR patients were treated in 2008-2010 and there may have been some shift in chemotherapy regimens compared with the time frame of the RCTs (late 1990s to early 2000s). Despite differences in study populations, including tumor types and chemotherapy regimens, the proportion of patients who experienced a hemoglobin decline from $>10 \mathrm{~g} / \mathrm{dL}$ to $<9 \mathrm{~g} / \mathrm{dL}$ was quite similar in the RCT and EMR database patients. The decline to $<9 \mathrm{~g} /$ dL occurred within 3 weeks in $35 \%$ to $40 \%$ of patients and $43 \%$ to $54 \%$ by 6 weeks. In the RCT dataset, the KaplanMeier estimate of transfusion rate was $20 \%(95 \% \mathrm{CI}=$ $16 \%, 24 \%)$ within 3 weeks and $32 \%(95 \% \mathrm{CI}=27 \%$, $36 \%)$ within 6 weeks.

Table 3 Time to first transfusion from first hemoglobin $<10 \mathrm{~g} / \mathrm{dL}$

\begin{tabular}{lc}
\hline Patients transfused,$\%(95 \% \mathrm{CI})$ & RCT patients $(n=411)$ \\
\hline Week 3 & $20(16,24)$ \\
Week 6 & $32(27,36)$ \\
Week 9 & $39(35,44)$ \\
Week 12 & $43(38,48)$ \\
\hline
\end{tabular}

$R C T$ randomized controlled trials, $C I$ confidence interval

${ }^{a}$ Values represent Kaplan-Meier percentage estimates
A strength of this analysis is the consistent results obtained with both the pooled RCT data and the realworld observational EMR data. Limitations of the use of EMR data for our analysis include a potential selection bias due to the voluntary provision of data by oncology practices (treatment patterns may be different in practices that do not participate), and the lack of data for treatments and procedures that are not reimbursable. For example, information on transfusions, inpatient chemotherapy, and oral chemotherapy (for which patients are sent elsewhere) as well as any procedures that occur in a hospital setting (e.g., transfusions) are not included in the EMR database. Therefore, the lack of transfusion data in the EMR did not allow us to determine if the correlation between the RCT and EMR data for hemoglobin decline from $<10 \mathrm{~g} / \mathrm{dL}$ to $<9 \mathrm{~g} / \mathrm{dL}$ also held for the time to first transfusion. Furthermore, this study did not address if specific populations of patients may be more likely to avoid a continued decline in their hemoglobin with a specific intervention, such as an ESA. Patients were required to be iron replete upon entry into all but one of the RCTs; however, although patients with other diagnosis codes for anemia were not included in the EMR data set, as it is an observational database, iron stores were not known.

It is interesting to note the similarity between the results of the RCT and the EMR data base, despite the difference in characteristics of the patients included in the two data sources. Patients enrolled in RCTs represent a select population of cancer patients. These patients tend to have no or few comorbidities and are also more likely to receive their chemotherapy at the full dose and on schedule, although this was not a specific requirement of these ESA clinical trials. In contrast, patients in an EMR database may be more representative of the general population and their treatment patterns may be more representative of community oncology clinic dosages and schedules. The similarity of results observed in the RCT patients and EMR database suggest that the rate of hemoglobin decline in this analysis can be generalized to most cancer patients, regardless of tumor type when receiving common myelosuppressive doublet chemotherapy regimens.

There are currently three options for treating chemotherapyinduced anemia in patients with advanced stage cancer who have hemoglobin levels between $9 \mathrm{~g} / \mathrm{dL}$ and $10 \mathrm{~g} / \mathrm{dL}$. The first option is to wait and watch for continued hemoglobin decline and worsening of anemia symptoms. The second option, for appropriate patients, is to initiate ESA therapy. The third option is to undergo RBC transfusion. Each of these options is associated with benefits and risks. The results of this analysis suggest that for patients with hemoglobin between $9 \mathrm{~g} / \mathrm{dL}$ and $10 \mathrm{~g} / \mathrm{dL}$ who are planned to receive further myelosuppressive chemotherapy, the first option of waiting and watching may result in over a third of patients falling to hemoglobin $<9 \mathrm{~g} / \mathrm{dL}$ within 3 weeks. The RCT data further suggest that $32 \%$ will need a transfusion within 6 weeks. Knowing that a potential 
hemoglobin response to ESAs takes time, waiting and watching may not be the optimal choice for patients with hemoglobin between $9 \mathrm{~g} / \mathrm{dL}$ and $10 \mathrm{~g} / \mathrm{dL}$ who want to minimize their risk of transfusion.

In summary, our results suggest that hemoglobin could rapidly decline when hemoglobin levels in cancer patients receiving chemotherapy drop to around $10 \mathrm{~g} / \mathrm{dL}$. This decline in hemoglobin was associated with a high rate of RBC transfusions.

Acknowledgments We thank Shawn Lee, $\mathrm{PhD}$, of Amgen Inc. and Julia R. Gage, PhD, on behalf of Amgen Inc. for assistance with writing the manuscript.

Funding This analysis was funded by Amgen Inc.

Conflict of interest R.P. is a consultant for Amgen and Roche. M.P., J.Q., and S.H. are employees of SDI Health, which received funding from Amgen for this study. J.L. and H.C. are employees and shareholders of Amgen Inc. J.V. received funding from Amgen Inc. for this study and holds an endowed chair funded by Eli Lilly and Astra Zeneca. The authors had access to the data, which are available to the journal editors upon request.

Open Access This article is distributed under the terms of the Creative Commons Attribution License which permits any use, distribution, and reproduction in any medium, provided the original author(s) and the source are credited.

\section{References}

1. Knight K, Wade S, Balducci L (2004) Prevalence and outcomes of anemia in cancer: a systematic review of the literature. Am J Med 116(Suppl 7A):11S-26S

2. (2001-2011) Aranesp ${ }^{\circledR}$ (darbepoetin alfa) prescribing information v25. Amgen Inc., Thousand Oaks, CA, USA

3. (2011) Procrit (epoetin alfa) prescribing information. Centocor Ortho Biotech Inc., Raritan, NJ, USA

4. European Medicines Agency. European public assessment reports for authorised medicinal products for human use. http://www. ema.europa.eu/ema/index.jsp?curl=pages/medicines/human/ medicines/000332/human_med_000651.jsp\&murl=menus/medicines/ medicines.jsp\&mid=WC0b01ac058001d124\&jsenabled=true. Accessed 7 February 2012

5. Elliott S, Pham E, Macdougall IC (2008) Erythropoietins: a common mechanism of action. Exp Hematol 36:1573-1584

6. Canon JL, Vansteenkiste J, Hedenus M, Gascon P, Bokemeyer C, Ludwig H, Vermorken J, Legg J, Pujol B, Bridges K (2011) Transfusion risk in cancer patients with chemotherapy-induced anemia when initiating darbepoetin alfa therapy at a baseline hemoglobin level of $<9 \mathrm{~g} / \mathrm{dL}$ versus 9 to $<10 \mathrm{~g} / \mathrm{dL}$ versus $>/$ $=10 \mathrm{~g} / \mathrm{dL}$ : an exploratory analysis of a phase 3 trial. Med Oncol. doi:10.1007/s12032-12011-10103-x

7. Eisterer W, Hussl C, Erb H, Haslbauer F, Sormann S, Braun S, Jaeger C (2011) RETRA: evaluating the transfusion rate with darbepoetin alfa $500 \mu \mathrm{g}$ every 3 weeks in anaemic cancer patients receiving chemotherapy. Curr Med Res Opin 27:355-363

8. Feinberg B, Gilmore J, Gondesen T, Jackson JH, Saleh M (2009) Impact of NCD guidelines on Medicare patients with chemotherapy-induced anemia receiving erythropoiesisstimulating agents: results from a community oncology practice. Community Oncol 6:257-261

9. Kotasek D, Steger G, Faught W, Underhill C, Poulsen E, Colowick AB, Rossi G, Mackey J (2003) Darbepoetin alfa administered every 3 weeks alleviates anaemia in patients with solid tumours receiving chemotherapy; results of a double-blind, placebocontrolled, randomised study. Eur J Cancer 39:2026-2034

10. Vansteenkiste J, Pirker R, Massuti B, Barata F, Font A, Fiegl M, Siena S, Gateley J, Tomita D, Colowick AB, Musil J (2002) Double-blind, placebo-controlled, randomized phase III trial of darbepoetin alfa in lung cancer patients receiving chemotherapy. J Natl Cancer Inst 94:1211-1220

11. Pirker R, Ramlau RA, Schuette W, Zatloukal P, Ferreira I, Lillie T, Vansteenkiste JF (2008) Safety and efficacy of darbepoetin alpha in previously untreated extensive-stage small-cell lung cancer treated with platinum plus etoposide. J Clin Oncol 26:2342-2349

12. Hedenus M, Hansen S, Taylor K, Arthur C, Emmerich B, Dewey C, Watson D, Rossi G, Osterborg A (2002) Randomized, dosefinding study of darbepoetin alfa in anaemic patients with lymphoproliferative malignancies. Br J Haematol 119:79-86

13. Hedenus M, Adriansson M, San Miguel J, Kramer MH, Schipperus MR, Juvonen E, Taylor K, Belch A, Altes A, Martinelli G, Watson D, Matcham J, Rossi G, Littlewood TJ (2003) Efficacy and safety of darbepoetin alfa in anaemic patients with lymphoproliferative malignancies: a randomized, double-blind, placebo-controlled study. Br J Haematol 122:394-403

14. Hernandez E, Ganly P, Charu V, Dibenedetto J, Tomita D, Lillie T, Taylor K (2009) Randomized, double-blind, placebo-controlled trial of every-3-week darbepoetin alfa 300 micrograms for treatment of chemotherapy-induced anemia. Curr Med Res Opin 25:2109-2120

15. Wu Y, Aravind S, Ranganathan G, Martin A, Nalysnyk L (2009) Anemia and thrombocytopenia in patients undergoing chemotherapy for solid tumors: a descriptive study of a large outpatient oncology practice database, 2000-2007. Clin Ther $31(\mathrm{Pt}$ 2):2416-2432

16. den Elzen WP, Gussekloo J (2011) Anaemia in older persons. Neth J Med 69:260-267

17. Vincent M, Dranitsaris G, Verma S, Lau C, Gascon P, Van Belle S, Ludwig H (2007) The development and validation of a prediction tool for chemotherapy-induced anemia in patients with advanced nonsmall cell lung cancer receiving palliative chemotherapy. Support Care Cancer 15:265-272 